\title{
Pseudolaric acid B inhibits proliferation in SW579 human thyroid squamous cell carcinoma
}

\author{
JINGHUA YU ${ }^{1 *}$, PEIYOU REN ${ }^{2 *}$, TING ZHONG $^{3 *}$, YALIN WANG $^{4}$, MINGHUI YAN $^{5}$, \\ BIANBIAN XUE ${ }^{6}$, RUI LI $^{2}$, CHUNYAN DAI ${ }^{1}$, CHUNYU LIU $^{7}$, \\ GUANG CHEN $^{2}$ and XIAO-FANG YU ${ }^{1,8}$ \\ ${ }^{1}$ Institute of Virology and AIDS Research; ${ }^{2}$ Department of Thyroid Surgery, The First Hospital of \\ Jilin University; ${ }^{3}$ Medicinal Chemistry, College of Pharmacy, Changchun University of Chinese Medicine; \\ ${ }^{4}$ Cancer Center, The First Hospital of Jilin University; ${ }^{5}$ Department of Biomedical Engineering, \\ College of Pharmacy, Jilin University; ${ }^{6}$ Department of Gastroenterology, The First Hospital of \\ Jilin University; ${ }^{7}$ Acupuncture Department, The Affiliated Hospital to Changchun University of \\ Chinese Medicine, Changchun, Jilin 130000, P.R. China; ${ }^{8}$ Department of Molecular Microbiology \\ and Immunology, Johns Hopkins Bloomberg School of Public Health, \\ Baltimore, MD 21205, USA
}

Received November 25, 2014; Accepted August 27, 2015

DOI: $10.3892 / \mathrm{mmr} .2015 .4418$

\begin{abstract}
Primary squamous cell carcinoma of the thyroid is a rare and aggressive type of neoplasm, which is routinely treated with surgery; however, despite this, survival time is not commonly more than six months. Thus, the aim of the present study was to determine the efficacy of pseudolaric acid (PAB) as a therapeutic agent. PAB is an antitubulin agent, and in the present study, inhibition of the SW579 thyroid squamous cell carcinoma cell line by PAB was investigated. PAB was found to inhibit SW579 cell growth in a time- and dose-dependent manner via interference in $\alpha$-tubulin polymerization. However, the inhibitory role of PAB in SW579 cells was not predominantly due to apoptosis, but was due to the cytostatic status resulting from cell cycle arrest. The present study proposes that this is the underlying mechanism of the antitumor properties of PAB. During cytostatis, autophagy was activated to sustain cell survival and SW579 cell migration was inhibited. Nuclear p53 expression was observed to
\end{abstract}

Correspondence to: Professor Guang Chen, Department of Thyroid Surgery, The First Hospital of Jilin University, 71 Xinmin Street, Changchun, Jilin 130000, P.R. China

E-mail:cg9293@sina.com

Professor Xiao-Fang Yu, Institute of Virology and AIDS Research, The First Hospital of Jilin University, 519 Dongming Zhu Street, Changchun, Jilin 130000, P. R. China

E-mail: xfyu@jhsph.edu

*Contributed equally

Key words: SW579 thyroid squamous cell carcinoma cell line, pseudolaric acid B, antitumor be reduced, however the role of reduced p53 requires further investigation. Therefore, PAB induced cytostasis, which inhibited SW579 cell growth and therefore may function as an antitubulin therapeutic agent.

\section{Introduction}

Human primary squamous cell carcinoma of the thyroid is a rare and aggressive type of neoplasm and although optimal treatment strategies are adopted, survival time is not expected to surpass six months. An effective therapeutic agent is therefore required. Pseudolaric acid $\mathrm{B}$ (PAB) (Fig. 1A) is a diterpene acid isolated from the root and trunk bark of Pseudolarix kaempferi Gordon (Pinaceae), known in Chinese as Tu-Jin-Pi, which may be administered to treat dermatological fungal infections. PAB has demonstrated potent inhibition of cell growth in vitro in a number of tumor cell lines (1-6). Thus, the aim of the present study was to investigate the antitumor effect of PAB on squamous cell carcinoma of the thyroid.

PAB is an antitubulin therapeutic agent (7-9) which, similar to other tubulin-associated agents, including taxanes (paclitaxel and docetaxel), the vinca alkaloids (vincristine and vinblastine) and nocodazole (10-12), suppresses microtubule dynamics to inhibit tumor growth in different cancer cell lines (7-9). Apoptosis, as one type of antitumor mechanism, has been the focus of many previous studies into antitumor therapeutic agent development $(13,14)$. Cell cycle arrest is another type of antitumor mechanism where cells are blocked from entering the next phase of the cell cycle and cannot proliferate. It has been reported that cell cycle arrest is often associated with apoptosis $(15,16)$ and/or autophagy $(17,18)$. Autophagy is the process by which cellular components are delivered to lysosomes for bulk degradation (19), in certain cases it appears to promote cell death and morbidity, however, in the majority of circumstances, 
autophagy promotes cell survival by adapting cells to stress (20). In addition, autophagy has been demonstrated to inhibit apoptosis, thereby decreasing the antitumor effect of therapeutic agents (21). The present study assessed the effect of PAB on the proliferation and autophagy-mediated cell survival of human primary squamous cell carcinoma.

\section{Materials and methods}

Materials. PAB was purchased from the National Institute for the Control of Pharmaceutical and Biological Products (Beijing, China) and dissolved in dimethyl sulfoxide (DMSO; Sigma-Aldrich, St. Louis, MO, USA) to make a stock solution. The concentration of DMSO was maintained at $<0.01 \%$ in all the cell cultures, and no detectable effect on cell growth or cell death was observed. Propidium iodode (PI), monodansylcadaverine (MDC), rhodamine 123, 3-methyladenine (3-MA), Hoechst 33258, RNase A and MTT were purchased from Sigma-Aldrich. An Annexin V:FITC apoptosis detection kit I was purchased from BD Biosciences (Franklin Lakes, NJ, USA). Mouse anti-human LC3A/B monoclonal antibody (66139-1-Ig), rabbit anti-human Beclin 1 polyclonal antibody (11306-1-AP), rabbit anti-human B-cell lymphoma 2 (Bcl-2) polyclonal antibody (12789-1-AP) and rabbit anti-human p53 polyclonal antibody (10442-1-AP) were purchased from ProteinTech Group, Inc (ProteinTech, Chicago, IL, USA). Rabbit anti-human histone H3 polyclonal antibody (A01502-40) was purchased from GenScript, Inc (Piscataway, NJ, USA). Mouse anti-human $\alpha$-tubulin monoclonal antibody (sc-23948), mouse anti human caspase-3 monoclonal antibody (sc-65497), fluorescein isothiocyanate (FITC)-labeled mouse secondary antibody (sc-2339), alkaline phosphatase (AP)-labeled rabbit anti-mouse (sc-358915) and goat anti-rabbit (sc-2057) secondary antibodies were purchased from Santa Cruz Biotechnology (Santa Cruz, Dallas, TX, USA).

Cell culture. SW579 human thyroid squamous cell carcinoma cells were obtained from American Type Culture Collection (Manassas, VA, USA), and cultured in L-15 medium (GE Healthcare Life Sciences, Logan, UT, USA) supplemented with $10 \%$ fetal calf serum (Gibco, Grand Island, NY, USA), $2 \mathrm{mM}$ glutamine (Gibco), penicillin $(100 \mathrm{U} / \mathrm{ml}$; Sigma-Aldrich) and streptomycin $(100 \mu \mathrm{g} / \mathrm{ml} ;$ Amresco, Solon, $\mathrm{OH}, \mathrm{USA}$ ), and maintained at $37^{\circ} \mathrm{C}$ without $\mathrm{CO}_{2}$ in a humidified atmosphere.

Cell growth inhibition test. The inhibition of cell growth was determined using an MTT assay. SW579 cells (1.0x10 cells/well) were seeded onto 96-well culture plates (Nalge-Nunc, Int., Penfield, NY. USA). Following incubation for $24 \mathrm{~h}$, different concentrations of PAB $(0,1.25,2.5,5,10,15$, $20,25,30$ or $40 \mu \mathrm{M}$ ) were added to the plates. Cell growth was measured at different time-points $(12,24,36$ and $48 \mathrm{~h}$ ) by addition of $20 \mu \mathrm{l}$ MTT $(5 \mathrm{mg} / \mathrm{ml})$ at $37^{\circ} \mathrm{C}$ for $3 \mathrm{~h}$, and DMSO $(150 \mu \mathrm{l})$ was added to dissolve the formazan crystals. Absorbance was measured at $492 \mathrm{~nm}$ using an enzyme-linked immunosorbent assay plate reader (iMark ${ }^{\mathrm{TM}}$; Bio-Rad, Hercules, CA, USA). The percentage of inhibition was calculated as follows: Cell death $(\%)=\left[\mathrm{A}_{492}(\right.$ control $)-\mathrm{A}_{492}($ sample $\left.)\right] /\left[\mathrm{A}_{492}(\right.$ control $)-\mathrm{A}_{492}(\mathrm{bl}$ ank)] x100.
Cell counting using a hemocytometer. Trypan blue (Sigma-Aldrich) was used to stain the cells. Live cells appeared colorless and bright (refractile) under phase contrast microscopy and the dead cells stained blue (non-refractile). Subsequent to staining with a final concentration $0.2 \%$ trypan blue, live cells were visualized and counted using a hemocytometer (Shanghai Qiujing Xue Qiu Ji Shu Ban, Shanghai, China). Decreasing ratio was calculated as follows: Decreasing ratio $(\%)=[$ cell number $($ control) - cell number $($ sample) $] /$ cell number (control) x 100 .

Immunofluorescence. SW579 cells $\left(5 \times 10^{5}\right)$ were placed on cover slips in a 6 -well plate. Following $24 \mathrm{~h}$ of cell culture, the cells were treated with $4 \mu \mathrm{M}$ PAB for $24 \mathrm{~h}$, washed with phosphate-buffered saline (PBS), fixed in $3.7 \%$ formaldehyde (Sigma-Aldrich) and rinsed three times in $1 \mathrm{X}$ PBS. The specimen was placed in blocking buffer (1X PBS, 5\% normal serum and $0.3 \%$ Triton X-100) for $60 \mathrm{~min}$, and subsequently incubated with $\alpha$-tubulin antibody (1:100 dilution) overnight at $4^{\circ} \mathrm{C}$. Following rinsing three times with $1 \mathrm{X}$ PBS, cells were incubated with FITC-conjugated mouse secondary antibody (1:1,000 dilution) for $2 \mathrm{~h}$ at room temperature in the dark. The secondary antibodies were aspirated and the cover slips were rinsed once in 1X PBS prior to staining with $5 \mathrm{mg} / \mathrm{l}$ Hoechst 33258 for $30 \mathrm{~min}$. The intensity of FITC staining was measured by fluorescence microscopy (Olympus CKX31, Olympus Corp., Tokyo, Japan) at an excitation wavelength of $505 \mathrm{~nm}$ with a 534-nm emission filter (Leica, Mannheim, Germany), Nuclear changes were observed by fluorescence microscopy at an excitation wavelength of $350 \mathrm{~nm}$ with a $460-\mathrm{nm}$ emission filter (Leica).

Flow cytometric analysis of the cell cycle. SW579 cells $\left(1.0 \times 10^{6}\right)$ were harvested and rinsed with PBS. The cell pellets were fixed in $70 \%$ ethanol at $4^{\circ} \mathrm{C}$ overnight. Following two washes with PBS, the cells were stained with $1.0 \mathrm{ml}$ PI solution containing $50 \mathrm{mg} / \mathrm{l} \mathrm{PI}, 1 \mathrm{~g} / \mathrm{l}$ RNase A and $3.8 \mathrm{mM} \mathrm{0.1 \%} \mathrm{Triton}$ $\mathrm{X}-100$ in sodium citrate, followed by incubation on ice in the dark for $30 \mathrm{~min}$. The samples were analyzed using a FACScan flow cytometer (BD Biosciences).

Observation of morphologic changes by light microscopy. SW579 cells $\left(5 \times 10^{5}\right.$ cells/well) were cultured in 6-well plates for $24 \mathrm{~h}$. The cells were treated with $4 \mu \mathrm{M} \mathrm{PAB}$ for 24 and $48 \mathrm{~h}$, and morphologic changes were observed by phase contrast microscopy (Olympus IX51, Olympus Corp.).

Observation of nuclear morphologic changes by fluorescence microscopy. SW579 cells $\left(5 \times 10^{5}\right)$ were placed on cover slips in a 6-well plate. Following a 24 -h cell culture, the cells were treated with $4 \mu \mathrm{M}$ PAB for 24 and $48 \mathrm{~h}$, washed with PBS, fixed in $3.7 \%$ formaldehyde for $1 \mathrm{~h}$ and stained with $5 \mathrm{mg} / 1$ Hoechst 33258 for $30 \mathrm{~min}$. Nuclear changes were observed by fluorescence microscopy (Olympus CKX31, Olympus Corp.) at an excitation wave length of $350 \mathrm{~nm}$ using a $460-\mathrm{nm}$ emission filter (Leica).

Annexin V-PI staining. Phosphatidylserine was detected using the Annexin V:FITC apoptosis detection kit I according to the manufacturer's instructions. The cells were trypsinized, 


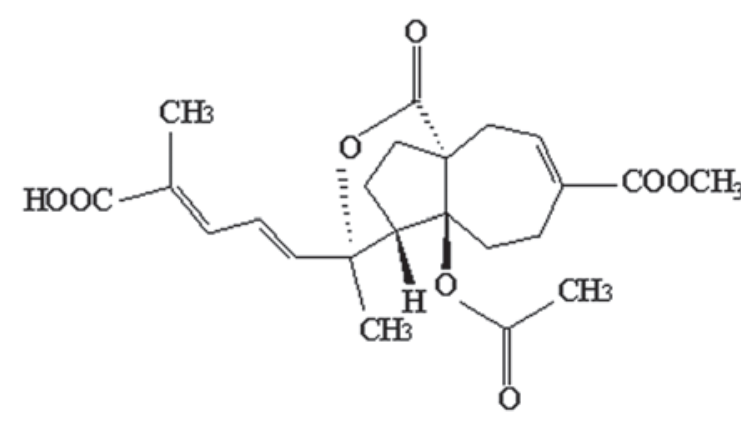

B

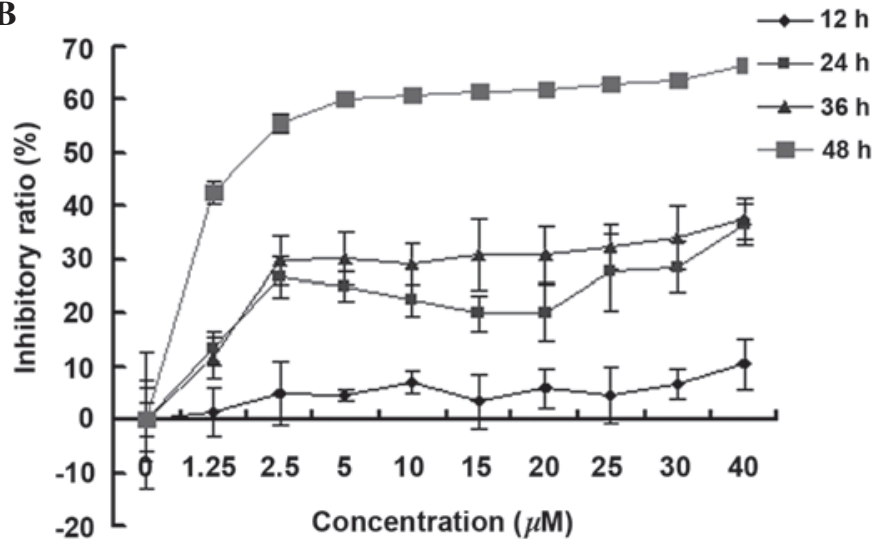

Figure 1. (A) Chemical structure of PAB and (B) inhibitory effect of PAB on SW579 cell growth at various time-points and concentrations. The cells ( $1 \times 10^{4}$ cells/well) were incubated with varying concentrations of PAB for 12, 24, 36 and 48 h. Growth inhibition was evaluated by the MTT assay. Results are expressed as means \pm standard deviation; $n=3$. PAB, psuedolaric acid B.

washed twice with cold PBS and resuspended in $200 \mu 1$ $1 \mathrm{X}$ binding buffer. Cell suspension $(100 \mu \mathrm{l})$ was transferred to a 5-ml culture tube and incubated with $5 \mu$ FITC-Annexin V and $10 \mu \mathrm{l}$ PI $(10 \mu \mathrm{g} / \mathrm{ml})$ for $15 \mathrm{~min}$ at room temperature in the dark. Binding buffer $(1 \mathrm{X} ; 500 \mu \mathrm{l})$ was added to each tube and the cells were analyzed by flow cytometry (FACSCalibur; BD Biosciences). Analysis was conducted according to the protocol of the Annexin V-PI apoptosis detection kit.

Determination of DNA fragmentation by agarose gel electrophoresis. Cells were trypsinized and the adherent and floating cells were collected by centrifugation at $1,000 \mathrm{x} \mathrm{g}$ for $5 \mathrm{~min}$. The procedure was conducted as described by $\mathrm{Yu}$ et al (4).

Observation of MDC staining by fluorescence microscopy. A fluorescent compound, MDC has been proposed as a tracer for autophagic vacuoles. SW579 cells were treated with $4 \mu \mathrm{M}$ PAB for $36 \mathrm{~h}$ and incubated with $0.05 \mathrm{mM} \mathrm{MDC}$ at $37^{\circ} \mathrm{C}$ for $1 \mathrm{~h}$. Following incubation, the cells were washed once with PBS. Intracellular MDC was measured by fluorescence microscopy (Olympus CKX31, Olympus Corp) at an excitation wavelength of $380 \mathrm{~nm}$ with a 525-nm emission filter (Olympus Corp).

Cell migration. Cells derived from human primary squamous cell carcinoma of the thyroid were cultured for $24 \mathrm{~h}$. Lines were arbitrarily scratched using a pipette tip, those of a similar width were selected, and the width was recorded at 12, 24, 36 and $48 \mathrm{~h}$ after PAB treatment by phase contrast microscopy (Olympus IX51, Olympus Corp.).

Western blot analysis of total protein expression and nuclear protein. SW579 cells $\left(1 \times 10^{6}\right)$ were cultured in a $25-\mathrm{ml}$ culture bottle for $24 \mathrm{~h}$ and were subsequently treated with $4 \mu \mathrm{M}$ PAB for $24 \mathrm{~h}$. Adherent and floating cells were collected by trypsinization and centrifugation, and frozen at $-80^{\circ} \mathrm{C}$. Western blot analysis was performed for total, cytoplasmic and nuclear proteins as described by $\mathrm{Yu}$ et al (4). Protein expression was detected using the corresponding primary polyclonal antibody at 1:1,000 dilution, except for LC3A/B monoclonal antibody, which was used at 1:200 dilution. Subsequently, blots were incubated with the corresponding
AP-conjugated secondary antibody at 1:1,000 dilution. Proteins were visualized using nitro blue tetrazolium chloride and 5-bromo-4-chloro-3-indoylphosphate and then scanned (Hp G4050; Hewlett-Packard, Palo Alto, CA, USA).

Statistical analysis. Statistical analyses were performed using Student's t-test through Microsoft Excel 2007 (Microsoft, Franklin, TN, USA). All data are representative of at least three independent experiments, and are expressed as the mean \pm standard deviation. $\mathrm{P}<0.05$ was considered to indicate a statistically significant difference.

\section{Results}

Inhibitory effect of PAB on SW579 cells. PAB is a diterpene acid (Fig. 1A), which has demonstrated an antitumor effect in diverse cancer cell lines (1-6). MTT analysis indicated that PAB inhibited SW579 cell growth in human thyroid squamous carcinoma cell line, in a time- and dose-dependent manner. The inhibitory effect of PAB was greater at $48 \mathrm{~h}$ compared with 12,24 and $36 \mathrm{~h}$, and the half maximal inhibitory concentration of PAB at $48 \mathrm{~h}$ was $4.26 \mu \mathrm{M}$ (Fig. 1B). During the current study, $4 \mu \mathrm{M}$ PAB was used in all experiments.

In the cell counting test, the cell number in the PAB-treated group was reduced at 12, 24, 36 and $48 \mathrm{~h}$, compared with the control group and the difference became more pronounced over time (Fig. 2A). In the PAB-treated group, the cell number at 12 and $24 \mathrm{~h}$ was decreased compared with that at $0 \mathrm{~h}$, with a decreasing ratio of 12.47 and $28.64 \%$, respectively (Fig. 2B), while from $24 \mathrm{~h}$ the cell number was stable, which indicated that from $24 \mathrm{~h}$, the cells had entered cytostatic status (Fig. 2B).

$P A B$ exposure altered tubulin distribution. Previous studies have reported that $\mathrm{PAB}$ is a tubulin-targeting agent (7), therefore, the effect of PAB on microtubule networks in SW579 cells was investigated by immunofluorescence staining of $\alpha$-tubulin. As presented in Fig. 3, treatment of SW579 cells with $4 \mu \mathrm{M}$ PAB for $24 \mathrm{~h}$ resulted in aggregation of the microtubule fibers. This disruption was accompanied by cellular deformation, consistent with the role of microtubules in the maintenance of cell shape (22). The cell nuclei were stained and the dots 
A

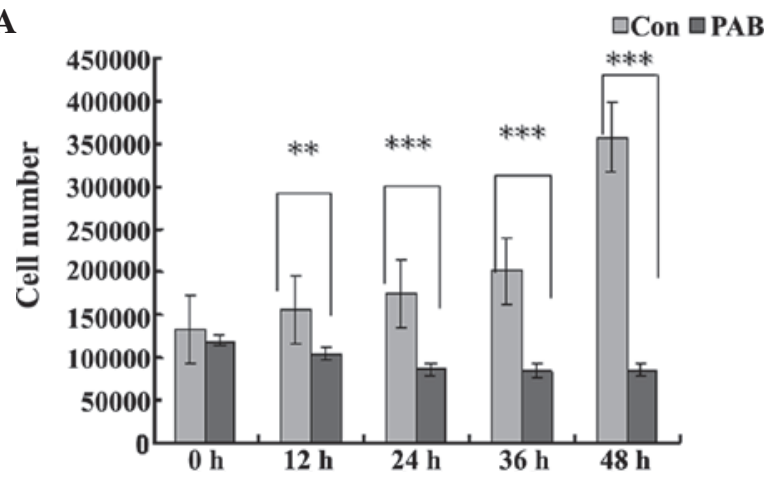

B

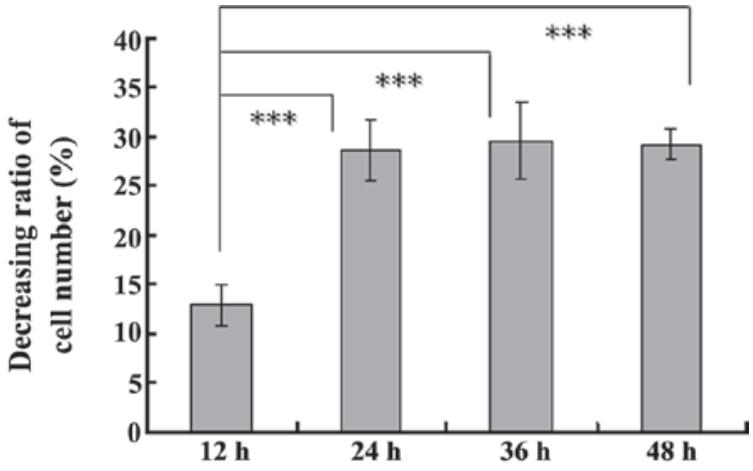

Figure 2. PAB decreases the number of SW579 cells. After 12, 24, 36 and $48 \mathrm{~h}$ of treatment with $4 \mu \mathrm{M}$ PAB, the cells were counted following trypan blue staining light microscopic observation. (A) Cell number; (B) The decreasing ratio of the cell number in the PAB treatment group was expressed as the percentage of the cell number at 12, 24, 36 and $48 \mathrm{~h}$ of PAB treatment with regard to the cell number at $0 \mathrm{~h}$ of PAB treatment. Values are expressed as the mean \pm standard deviation; $\mathrm{n}=3 .{ }^{* *} \mathrm{P}<0.01 ;{ }^{* * *} \mathrm{P}<0.001$. $\mathrm{PAB}$, pseudolaric acid $\mathrm{B} ;$ Con, control.
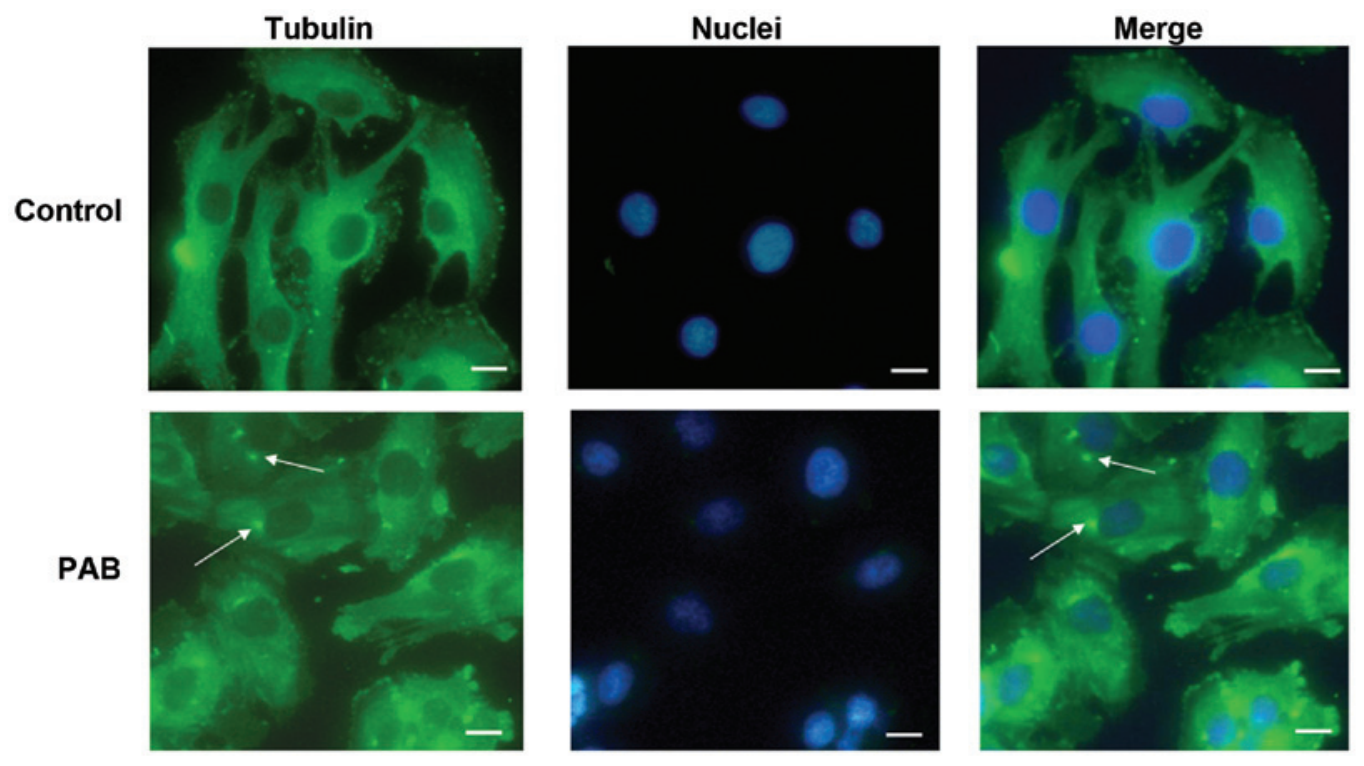

Figure 3. $\alpha$-Tubulin distribution analysis of PAB-treated SW579 cells by fluorescence microscopy. SW579 cells were treated with PAB (4 $\mu$ M) for 24 h. Control cells were treated with dimethyl sulfoxide. Cells were fixed in $4 \%$ paraformaldehyde, and stained with anti- $\alpha$-tubulin antibodies prior to being co-stained with fluorescein isothiocyanate-labeled secondary antibody and Hoechst 33258 (blue). Merged images of $\alpha$-tubulin and DNA staining are presented. Arrows indicate aggregated $\alpha$-tubulin. Data are representative of three individual experiments; $\mathrm{n}=3$. Scale bar=15 $\mu \mathrm{m}$. PAB, pseudolaric acid B.

of aggregation of the microtubule fibers were observed to be located near to the cell nuclei (Fig. 3).

$P A B$ induced $G_{2} / M$ cell cycle arrest. To further investigate the mechanism of cell growth inhibition by PAB, the cell cycle was analyzed flow cytometry. Following $4 \mu \mathrm{M}$ PAB treatment for $36 \mathrm{~h}$, the quantity of DNA doubled compared with the control group (Fig. 4A), indicating that PAB-treated cells may be arrested at the $G_{2} / M$ phase. In the histogram analysis, it was observed that from $12 \mathrm{~h}, \mathrm{PAB}$ began to increase the percentage of cells in the $\mathrm{G}_{2} / \mathrm{M}$ phase of the cell cycle (Fig. 4B).

PAB did not induce apoptosis. To determine that there was no apoptosis occurring, cell and nuclear morphology were observed. At 24 and 48 h no characteristics of cell apoptosis were evident, such as the appearance of apoptotic bodies or condensed cell nuclei in the PAB-treated group (Fig. 5A). While at 24 and $48 \mathrm{~h}$ after PAB treatment, cell nuclei did not become brighter indicating that no apoptosis was occurring; however, multinuclear cells appeared at 48 h (Fig. 5B). Further analysis was conducted to confirm whether apoptosis was involved in the decreasing cell number following PAB treatment. Annexin V-PI staining indicated that no apoptosis was occurring following PAB treatment for $12 \mathrm{~h}$, and the early apoptotic ratio increased from 0 to $1.95 \%$ in the PAB-treated cells compared with the control group (Fig. 6A). Agarose gel electrophoresis was also conducted and no DNA ladder was observed at $0,12,24,36$ or $48 \mathrm{~h}$ subsequent to PAB treatment (Fig. 6B). In addition, at $24 \mathrm{~h}$ following PAB treatment, the expression of active caspase-3 was not increased compared with the control group (Fig. 6C).

$P A B$ induced autophagy at $24 \mathrm{~h}$ following $P A B$ treatment. It was demonstrated that $4 \mu \mathrm{M}$ PAB increased MDC-positive staining, which marked autophagy (Fig. 7A). Furthermore, at $24 \mathrm{~h}$ the level of LC3-II expression increased, which indicated 


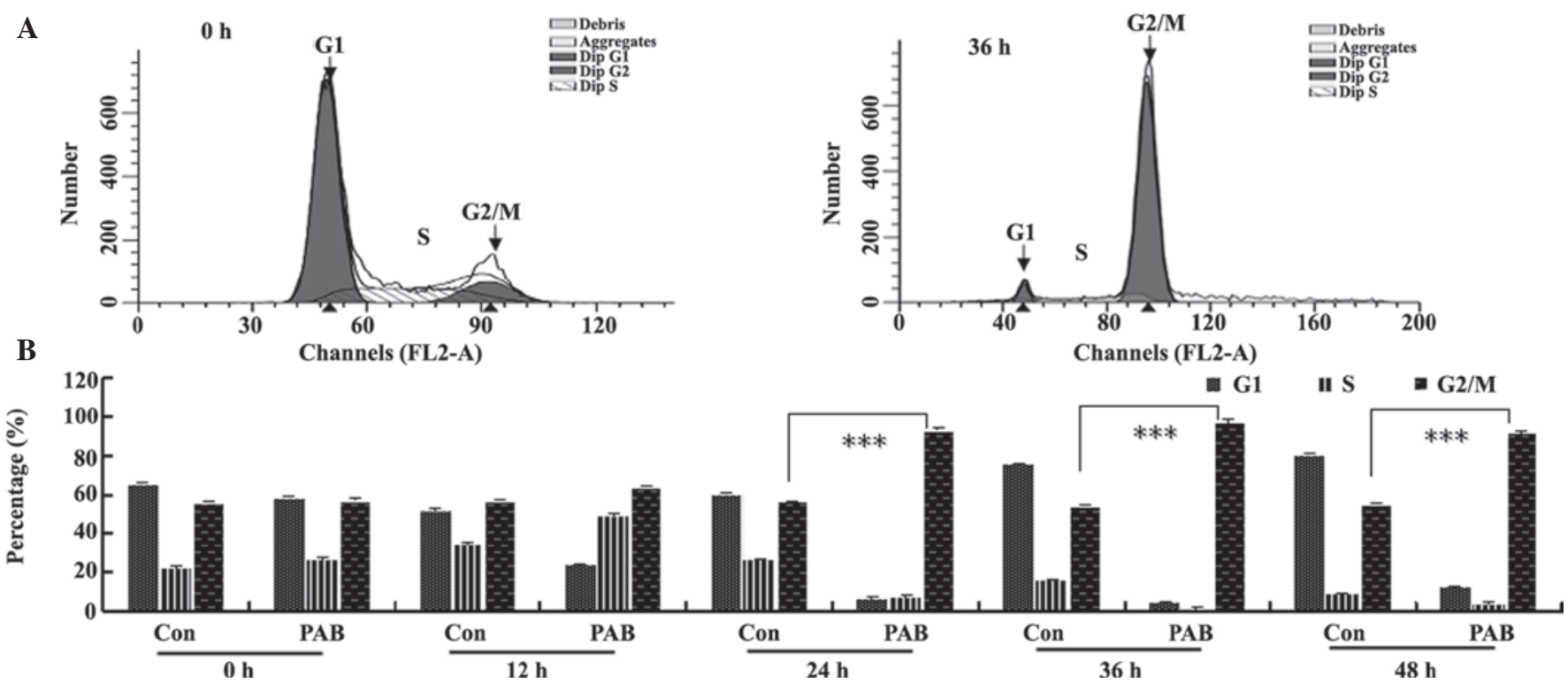

Figure 4. PAB promoted $\mathrm{G}_{2} / \mathrm{M}$ cell cycle arrest. (A) At $36 \mathrm{~h}, \mathrm{PAB}$ induced cell cycle arrest in $\mathrm{G} 2 / \mathrm{M}$ phase. (B) Flow cytometric histogram analysis indicating that between 12 and $48 \mathrm{~h}, 4 \mu \mathrm{M}$ PAB induced cell cycle arrest. Data are presented as means \pm standard deviation; $\mathrm{n}=3$. ${ }^{* * *} \mathrm{P}<0.001$. PAB, pseudolaric acid $\mathrm{B}$; FL2-A, FL2-area; Con, control.

A
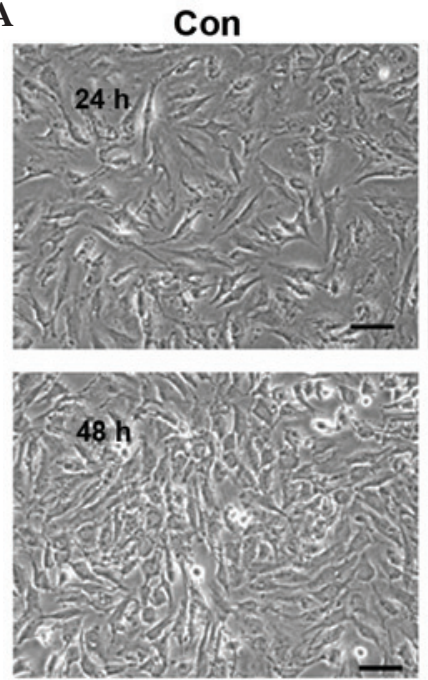

PAB
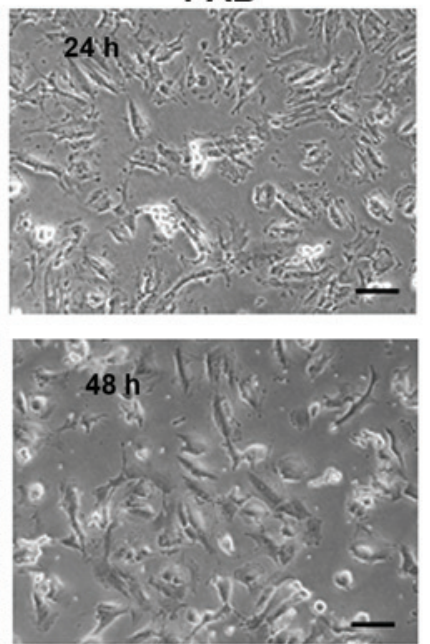

B
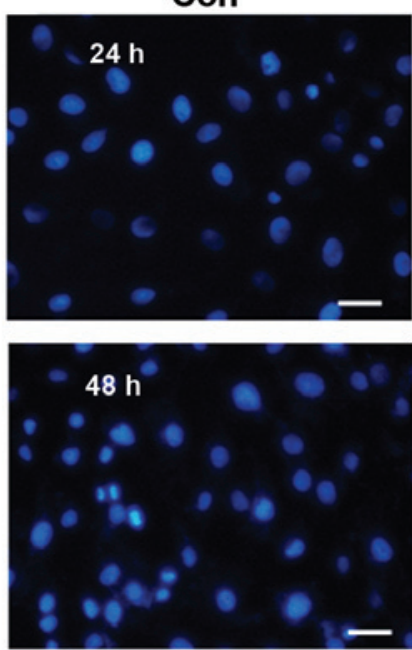

PAB
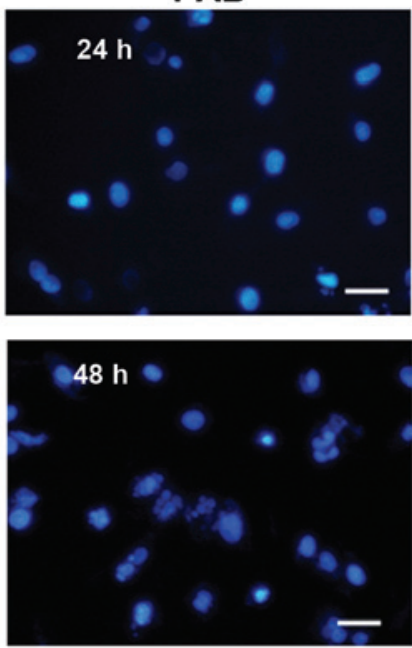

Figure 5. Cell and nuclear morphology were visualized following PAB treatment. (A) After 24 and $48 \mathrm{~h}$ of PAB treatment, morphological changes in SW579 cells were visualized by phase contrast microscopy. (B) Cells were stained using Hoechst 33258 to observe nuclear changes and imaged via fluorescence microscopy. Data are representative of three individual experiments; $\mathrm{n}=3$. Scale bar, $30 \mu \mathrm{m}$. PAB, pseudolaric acid B; Con, control.

autophagy (Fig. 7B). The role of autophagy-induction by PAB treatment was unknown, thus the autophagy inhibitor, 3-MA ( $2 \mathrm{mM}$ ) was used to inhibit autophagy and a decreased cell survival rate was identified (Fig. 7C).

$P A B$ inhibited cell migration. The effect of PAB exposure on inhibition of SW579 cell migration was investigated in the current study. It was demonstrated that SW579 cells were able to migrate as, over time, the arbitrarily scratched lines gradually disappeared in the control cells, whereas the scratched lines remained in the PAB-treated cells (Fig. 8).

$P A B$ did not regulate Bcl-2 and Beclin-1 expression levels, but decreased the expression of nuclear p53. It was found that PAB exposure did not regulate the expression of Bcl-2 and
Beclin-1 after $24 \mathrm{~h}$ treatment (Fig. 9A). However, the expression of nuclear p53 was reduced by PAB treatment at $24 \mathrm{~h}$ (Fig. 9B).

\section{Discussion}

PAB has been demonstrated to exert a potent antitumor effect on MCF-7 human breast cancer cells, HeLa human cervical cancer cells and A375 human melanoma cells (1-6). Compared with these cell lines, human primary squamous cell carcinoma of the thyroid is a rare, and often ignored, example of a cell line for a neoplasm demonstrating aggressive behavior. Despite optimal surgical treatment being adopted, survival of greater than six months with this aggressive malignancy is unlikely. An effective therapeutic agent is required to improve 
A
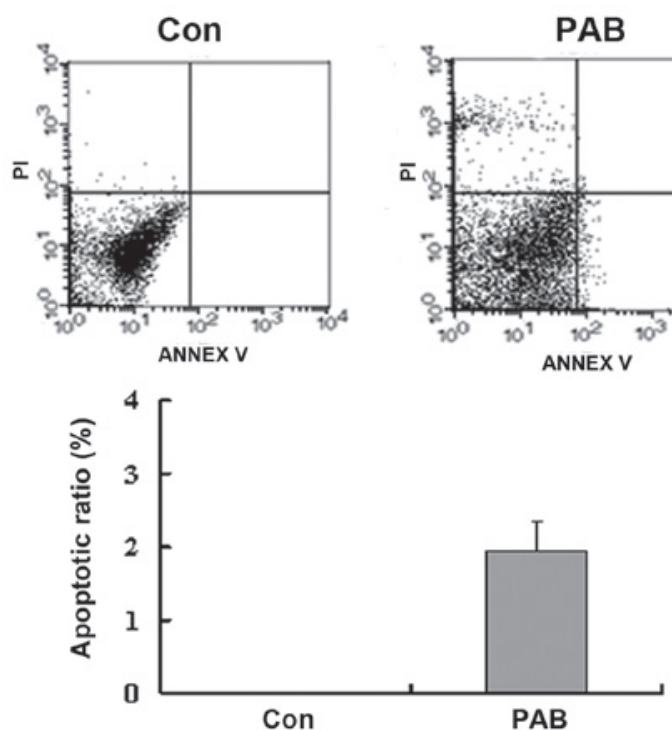

B

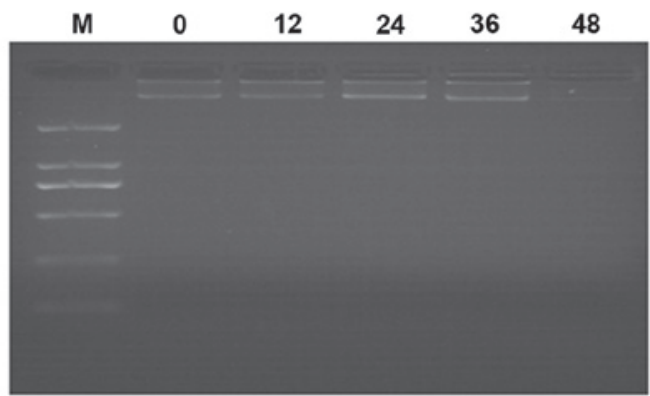

C

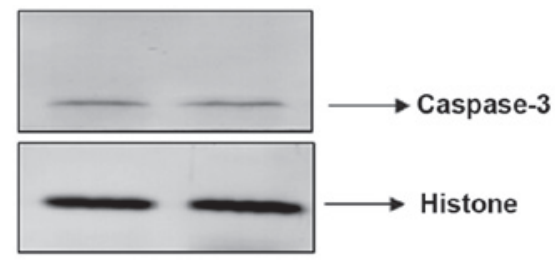

Figure 6. PAB did not induce apoptosis. (A) No phosphatidylserine translocation was observed in PAB-treated cells. At $12 \mathrm{~h}$ after PAB treatment, the cells were washed with phosphate-buffered saline and incubated with a fluorescein isothiocyanate-labeled Annexin V and stained with PI. The cells were analyzed by flow cytometry. The Annexin V-positive and PI-negative cells were considered to be early-phase apoptotic cells. The Annexin V-positive and PI-positive cells were considered to be apoptotic cells in a later phase. (B) No fragmentation of chromosomal DNA was observed in PAB-treated cells. DNA was extracted from the cells at different time-points $(0,12,24,36$ and $48 \mathrm{~h})$ and analyzed by agarose gel electrophoresis. (C) Expression of active caspase-3. At $24 \mathrm{~h}$ after PAB treatment, the cells were lysed and western blotting was conducted to determine protein expression. Data are representative of three individual experiments; $\mathrm{n}=3$. PAB, pseudolaric acid B; PI, propidium iodide; Con, control; M, marker.

A
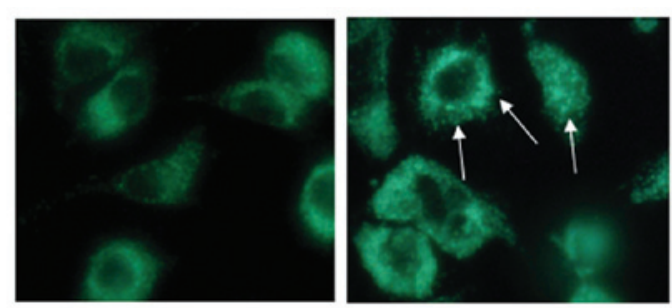

C

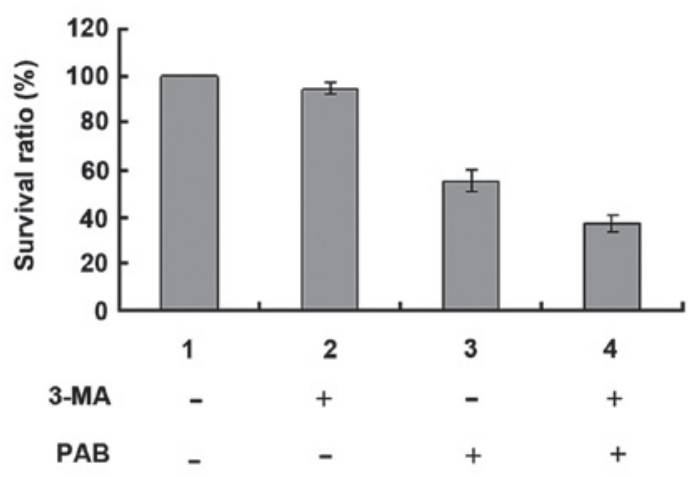

B

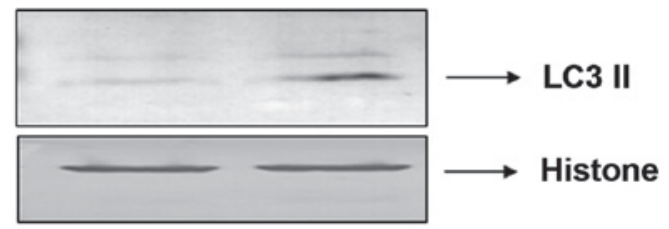

Figure 7. PAB increased the ratio of autophagy and inhibition of autophagy increased cell death. (A) At 24 h, $4 \mu \mathrm{M}$ PAB increased the positive staining (indicated by the arrows) of monodansylcadaverine as observed by fluorescence microscopy. (B) Expression of LC3-II. The cells were lysed and western blotting was performed to detect protein expression $24 \mathrm{~h}$ after PAB treatment. Histone served as a loading control. (C) Growth inhibition was evaluated by the MTT assay at $24 \mathrm{~h}$ following PAB treatment, using the autophagy inhibitor, $3-\mathrm{MA}$. Data are presented as means \pm standard deviation; $\mathrm{n}=3$. ${ }^{* *} \mathrm{P}<0.01$. $\mathrm{PAB}$, pseudolaric acid B; 3-MA, 3-methyladenine.

treatment success. In the present study, PAB was demonstrated to exert an antitumor effect on the SW579 cells from primary squamous cell carcinoma of the thyroid.

PAB exposure inhibited SW579 growth in a time- and dose-dependent manner, following $48 \mathrm{~h}$ of PAB treatment, the antitumor effect was marked, indicating PAB was increasingly effective over time. Subsequently, a cell counting test was conducted to further observe the inhibitory effect of PAB. In the PAB-treated group, it was observed that the cell number decreased at 12 and $24 \mathrm{~h}$ compared with at $0 \mathrm{~h}$, however the cell number remained stable from 24 to $48 \mathrm{~h}$. This suggests that from 0 to $24 \mathrm{~h}$, a small quantity of cell 
$12 \mathrm{~h}$
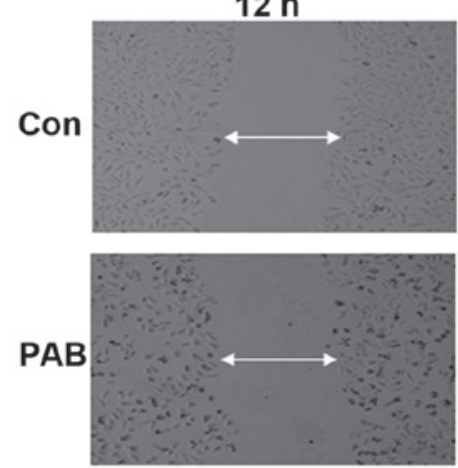

$24 \mathrm{~h}$
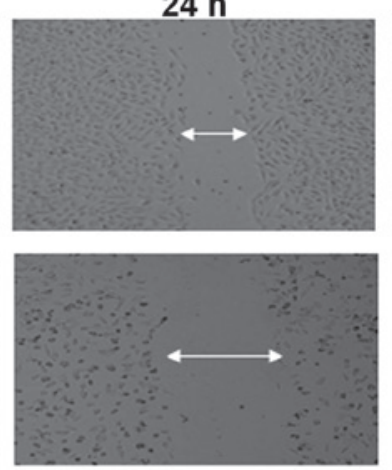

$36 \mathrm{~h}$
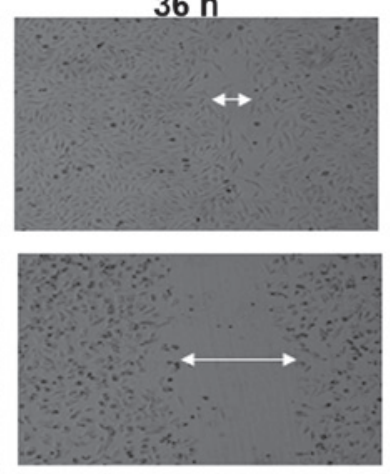
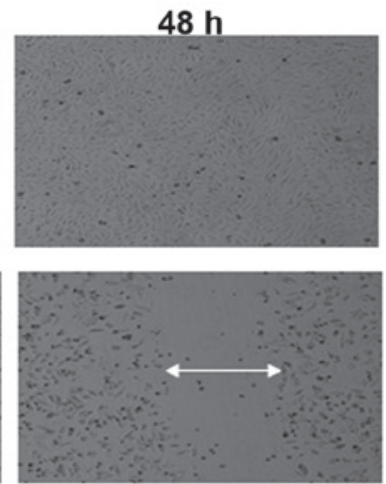

Figure 8. PAB inhibited cell migration. A pipette was used to scratch an arbitrary line through the Con and PAB-treated cells. The width of the scratch was recorded at 12, 24, 36 and $48 \mathrm{~h}$. Data are representative of three individual experiments; $\mathrm{n}=3$. PAB, pseudolaric acid B; Con, control.

A

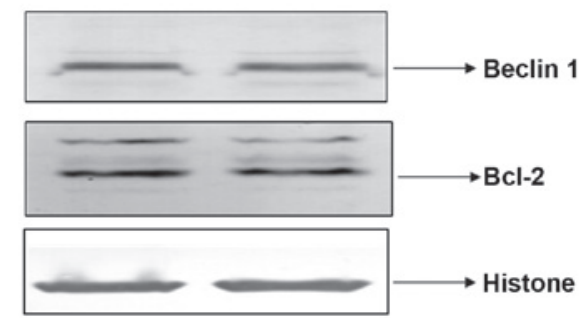

B

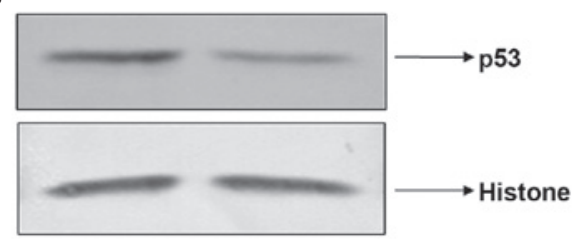

Figure 9. Expression of Bcl-2 and Beclin-1, and the expression of nuclear p53 at $24 \mathrm{~h}$ following pseudolaric acid B treatment. (A) Expression of Bcl-2 and Beclin-1. The cells were lysed and western blot analysis was performed to detect protein expression. (B) The nuclear protein was extracted and the expression of p53 was detected. Histone served as a loading control. Data are representative of three individual experiments; $\mathrm{n}=3$.

death occurred, however from 24 to $48 \mathrm{~h}$ cells entered a cytostatic state. Thus, indicating that the inhibitory effect of PAB originates from control of cell growth and cytostatic activity. It has been reported that PAB exerts its antitumor effects via disturbing tubulin function (7), therefore the effect of PAB on tubulin function was investigated in the SW579 cell line in the present study. PAB exposure resulted in the aggregation of microtubule fibers near to the nuclei, which is consistent with previous reports (7). The cytostatic status induced by PAB was analyzed by determining the cell cycle distribution following PAB treatment, and it was observed that from $12 \mathrm{~h}$ after PAB treatment the percentage of cells in the $G_{2} / M$ phase was increased, indicating that the cytostatic status resulted from cell cycle arrest in the $\mathrm{G}_{2} / \mathrm{M}$ phase. At 12 and $24 \mathrm{~h}$, in the PAB-treated group the cell number was reduced compared with that at $0 \mathrm{~h}$, which indicated that cell death had occurred. Apoptosis is one type of death mechanism, thus cell and nuclear morphologic analysis, Annexin V-PI staining and gel electrophoresis were conducted to detect apoptosis. However, in the cell morphologic analysis, no obvious apoptotic bodies were observed. In the nuclear morphologic analysis, the

nuclei were not condensed and bright nuclear fragmentation was not observed. The Annexin V-PI test did not identify phosphatidylserine translocation, and in gel electrophoresis, no DNA fragmentation was apparent following PAB treatment for 0-48 h. Therefore, PAB did not induce apoptosis in the SW579 cell line, thus the mechanism for reduced cell number at 12 and $24 \mathrm{~h}$ after PAB treatment was not apoptosis, but another mechanism of cell death, such as necrosis. It has been previously reported that autophagy occurs when the cell is arrested during the cell cycle (23). In the present study, PAB treatment increased MDC staining and LC3-II protein expression, which marks autophagy. Inhibition of autophagy using the autophagy inhibitor, 3-MA, increased cell death, indicating that during cytostasis autophagy sustains cell survival. In the present study it was observed that PAB inhibited cell migration; a notable finding due to the aggressive nature of human primary squamous cell carcinoma of the thyroid.

The mechanism of PAB as an antitumor therapeutic agent was also investigated. Beclin-1 and Bcl-2 are autophagy-associated proteins, however, the expression of these proteins was not affected by PAB treatment, suggesting that PAB-induced autophagy was not associated with the expression of Beclin-1 and Bcl-2. Bcl-2 expression is decreased when apoptosis occurs (24) and the current study demonstrated that PAB exposure did not induce apoptosis. The p53 protein is crucial in multicellular organisms, where it regulates the cell cycle and, thus, functions as a tumor suppressor, preventing cancer (25). However, it was found that following PAB treatment, the expression of nuclear p53 was decreased. The role of decreased nuclear p53 remains unknown and requires further investigation. It was hypothesized that decreased expression of p53 may be associated with the lack of apoptosis in PAB-treated SW579 cells. In conclusion, PAB exerted an antitumor effect via inducing a cytostatic state in SW579 cells from the human thyroid squamous cell carcinoma cell line.

In conclusion, the present study demonstrated that the antitubulin agent PAB exerted cytostatic effects on primary squamous cell carcinoma of the thyroid with the involvement of autophagy and a reduced cell migratory ability. PAB is therefore a candidate drug for treating primary squamous cell carcinoma of the thyroid. 


\section{Acknowledgements}

The present study was supported by funding from Jilin Provincial Science and Technology Department (grant no. 20140204004YY), the National Natural Science Foundation of China (grant no. 81301416), the Postdoctoral Science Foundation of China (grant no. 2014M561302), the Chinese Ministry of Science and Technology (grant nos. 2012CB911100 and 2013ZX10001005), the State Grade III Laboratory of Traditional Chinese Medicine, the Immunology and Molecular Biology Laboratory and the Key Laboratory of Molecular Virology of Jilin Province (grant no. 20102209).

\section{References}

1. Pan DJ, Li ZL, Hu CQ, Chen K, Chang JJ and Lee KH: The cytotoxic principles of Pseudolarix kaempferi: Pseudolaric acid-A and -B and related derivatives. Planta Med 56: 383-5, 1990.

2. Gong XF, Wang MW, Tashiro S, Onodera S and Ikejima T: Pseudolaric acid B induces apoptosis through p53 and Bax/Bcl-2 pathways in human melanoma A375-S2 cells. Arch Pharm Res 28: 68-72, 2005.

3. Gong $X$, Wang $M$, Tashiro $S$, Onodera $S$ and Ikejima T: Involvement of JNK-initiated p53 accumulation and phosphorylation of p53 in pseudolaric acid B induced cell death. Exp Mol Med 38: 428-34, 2006.

4. Yu JH, Cui Q, Jiang YY, Yang W, Tashiro S, Onodera S and Ikejima T: Pseudolaric acid B induces apoptosis, senescence, and mitotic arrest in human breast cancer MCF-7. Acta Pharmacol Sin 28: 1975-83, 2007.

5. Yu J, Li X, Tashiro S, Onodera S and Ikejima T: Bcl-2 family proteins were involved in pseudolaric acid B-induced autophagy in murine fibrosarcoma L929 cells. J Pharmacol Sci 107: 295-302, 2008

6. Yu JH, Wang HJ, Li XR, Tashiro S, Onodera S and Ikejima T: Protein tyrosine kinase, JNK, and ERK involvement in pseudolaric acid B-induced apoptosis of human breast cancer MCF-7 cells. Acta Pharmacol Sin 29: 1069-1076, 2008.

7. Wong VK, Chiu P, Chung SS, Chow LM, Zhao YZ, Yang BB and Ko BC: Pseudolaric acid B, a novel microtubule-destabilizing agent that circumvents multidrug resistance phenotype and exhibits antitumor activity in vivo. Clin Cancer Res 11 6002-6011, 2005.

8. Sarkar T, Nguyen TL, Su ZW, Hao J, Bai R, Gussio R, Qiu SX and Hamel E: Interaction of pseudolaric acid B with the colchicine site of tubulin. Biochem Pharmacol 84: 444-450, 2012.

9. Tong YG, Zhang XW, Geng MY, Yue JM, Xin XL, Tian F, Shen $\mathrm{X}$, Tong LJ, Li MH, Zhang C, et al: Pseudolarix acid B, a new tubulin-binding agent, inhibits angiogenesis by interacting with a novel binding site on tubulin. Mol Pharmacol 69: 1226-1233, 2006.

10. Blagosklonny MV and Fojo T: Molecular effects of paclitaxel: Myths and reality (a critical review). Int J Cancer 83: 151-156, 1999.
11. Horwitz SB: Mechanism of action of taxol. Trends Pharmacol Sci 13: 134-136, 1992.

12. Jordan MA and Wilson L: Microtubules as a target for anticancer drugs. Nat Rev Cancer 4: 253-265, 2004.

13. Li FF, Yi S, Wen L, He J, Yang LJ, Zhao J, Zhang BP, Cui GH and Chen Y: Oridonin induces NPM mutant protein translocation and apoptosis in NPM1c+ acute myeloid leukemia cells in vitro. Acta Pharmacol Sin 35: 806-813, 2014.

14. Qi M, Yao G, Fan S, Cheng W, Tashiro S, Onodera S and Ikejima T: Pseudolaric acid B induces mitotic catastrophe followed by apoptotic cell death in murine fibrosarcoma L929 cells. Eur J Pharmacol 683: 16-26, 2012.

15. Han Y, Yang YN, Yuan HH, Zhang TT, Sui H, Wei XL, Liu L, Huang P, Zhang WJ and Bai YX: UCA1, a long non-coding RNA up-regulated in colorectal cancer influences cell proliferation, apoptosis and cell cycle distribution. Pathology 46: 396-401, 2014.

16. Lee H, Lee H, Chin H, Kim K and Lee D: ERBB3 knockdown induces cell cycle arrest and activation of Bak and Bax-dependent apoptosis in colon cancer cells. Oncotarget 5: 5138-5152, 2014.

17. Ahn JH, Lee YW, Ahn SK and Lee M: Oncogenic BRAF inhibitor UAI-201 induces cell cycle arrest and autophagy in BRAF mutant glioma cells. Life Sci 104: 38-46, 2014.

18. Wang R, Xiao X, Wang PY, Wang L, Guan Q, Du C and Wang XJ: Stimulation of autophagic activity in human glioma cells by anti-proliferative ardipusilloside I isolated from Ardisia pusilla. Life Sci 110: 15-22, 2014.

19. Lee YJ, Won AJ, Lee J, Jung JH, Yoon S, Lee BM and Kim HS: Molecular mechanism of SAHA on regulation of autophagic cell death in tamoxifen-resistant MCF-7 breast cancer cells. Int J Med Sci 9: 881-893, 2012.

20. Lee YZ, Yang CW, Chang HY, Hsu HY, Chen IS, Chang HS, Lee CH, Lee JC, Kumar CR, Qiu YQ, et al: Discovery of selective inhibitors of Glutaminase-2, which inhibit mTORC1, activate autophagy and inhibit proliferation in cancer cells. Oncotarget 5: 6087-6101, 2014

21. He H, Feng YS, Zang LH, Liu WW, Ding LQ, Chen LX, Kang N, Hayashi T, Tashiro S, Onodera S, et al: Nitric oxide induces apoptosis and autophagy; autophagy down-regulates NO synthesis in physalin A-treated A 375-S2 human melanoma cells. Food Chem Toxicol 71: 128-135, 2014.

22. Liu F, Xuan A, Chen Y, Zhang J, Xu L, Yan Q and Long D: Combined effect of nerve growth factor and brain-derived neurotrophic factor on neuronal differentiation of neural stem cells and the potential molecular mechanisms. Mol Med Rep 10: 1739-1745, 2014.

23. Santi SA and Lee H: Ablation of Akt2 induces autophagy through cell cycle arrest, the downregulation of p70S6K, and the deregulation of mitochondria in MDA-MB231 cells. PLoS One 6: e14614, 2011.

24. Xu LF, Wu ZP, Chen Y, Zhu QS, Hamidi S and Navab R: MicroRNA-21 (miR-21) regulates cellular proliferation, invasion, migration, and apoptosis by targeting PTEN, RECK and Bcl-2 in lung squamous carcinoma, Gejiu City, China. PLoS One 9: e103698, 2014.

25. Lee YJ, Park IS, Lee YJ Shim JH, Cho MK, Nam HS, Park JW, Oh MH and Lee SH: Resveratrol contributes to chemosensitivity of malignant mesothelioma cells with activation of p53. Food Chem Toxicol 63: 153-160, 2014. 